\title{
Fully graph sensitivity solution of the switched circuits by two-graph
}

\author{
BOHUMIL BRTNÍK \\ Department of Electrical Engineering \\ University of Pardubice, Faculty of Electrical Engineering and Computer Science \\ náměstí Čs. Legií 565, Pardubice \\ CZECH REPUBLIC
}

\begin{abstract}
The most general parameter of the electronic circuit is its sensitivity. Sensitivity analysis helps circuit designers to determine boundaries to predict the variations that a particular design variable will generate in a target specifications, if it differs from what is previously assumed. There are two basic methods for calculating the sensitivity: matrix methods and graph methods. The method described in this article is based on a graph, that contains separate input ad output nodes for each phase. This makes it possible to determine the transmission sensitivity even between partial switching phases. The described fully-graph method is suitable for switched current circuits and switched capacitors circuits, too.
\end{abstract}

Keywords - Sensitivity, switched capacitors, switched currents, graph method.

Received: February 4, 2021. Revised: August 22, 2021. Accepted: September 21, 2021. Published: September 27, 2021.

\section{Introduction}

The basic parameter of the electronic circuit is

its sensitivity. Sensitivity analysis is useful tool for identifying tolerances of circuit elements. Some graph methods for sensitivity analysis were described in [1], [2], [3]. Sensitivity analysis is very important in switched circuit design, because it helps us to optimize the behavior of a given switched circuit by showing us which components of the entire systems are more sensitive. The most general element for switched circuits is a transconductance with input and output branches in different phases [4]. The main disadvantage of the previously published graphical method for switched circuits (for example [5] for SC circuits) is the impossibility to determine the sensitivity between the two different switching phases. Therefore, the graphs so far published do not include separate output and input nodes for different switching phases.

For switched currents circuits the expression that gives the sensitivity of the transfer $\mathrm{F}_{\mathrm{Ob}, \mathrm{Ea}}$ relative to a conductance $G$ (control current in phase $E$ at branch a and output current in phase $\mathrm{O}$ at branch $\mathrm{b}$ ) is

$$
\mathrm{S}_{\mathrm{G}}^{\mathrm{F}_{\mathrm{Ob}, \mathrm{Ea}}}=\frac{\mathrm{G}}{\mathrm{F}} \frac{\partial \mathrm{F}}{\partial \mathrm{G}}
$$

For switched capacitors circuits the sensitivity of the transfer $\mathrm{F}_{\mathrm{Ob}, \mathrm{Ea}}$ relative to a capacitance $\mathrm{C}$ (the control voltage is control voltage is in phase $\mathrm{E}$ at node $\mathrm{a}$ and output voltage in phase $\mathrm{O}$ at node $\mathrm{b}$ ) is

$$
\mathrm{S}_{\mathrm{C}}^{\mathrm{F}_{\mathrm{Ob}, \mathrm{Ea}}}=\frac{\mathrm{C}}{\mathrm{F}} \frac{\partial \mathrm{F}}{\partial \mathrm{C}}
$$

\section{The Transfer Function and the Sensitivity Determinations}

For example, the relative sensitivity $\mathrm{S}_{\mathrm{C}}^{\mathrm{F}}$ of the

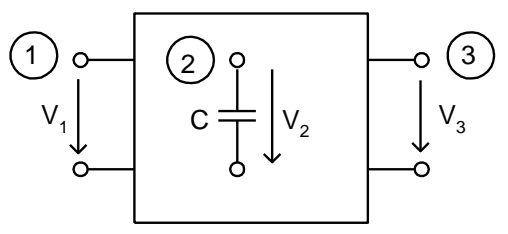

Fig. 1. The general circuit and illustrating the members of the equations

circuit is given as (3)

$$
\mathrm{S}_{\mathrm{C}}^{\mathrm{F}}=\frac{\mathrm{C}}{\mathrm{F}} \frac{\partial \mathrm{F}}{\partial \mathrm{C}}
$$

where $\mathrm{F}$ is transfer function, $\mathrm{C}$ is circuit element. The derivation $\frac{\partial \mathrm{F}}{\partial \mathrm{C}}$ for circuit, which is described by simplest Fig 1, where C capacitance in branch, for example $\frac{\partial \mathrm{F}}{\partial \mathrm{c}_{23}}$ is given as follows (4).

$$
\begin{aligned}
& \quad \begin{array}{lcr}
a & b & c \\
d & C+e & f \\
g & h & i
\end{array} \mid= \\
& \quad=a \cdot e \cdot i+b \cdot f \cdot g+d \cdot h \cdot c-g \cdot e \cdot c \\
& \quad-a \cdot f \cdot h+a \cdot C \cdot i-g \cdot C \cdot c=
\end{aligned}
$$




$$
\begin{gathered}
=a \cdot e \cdot i+b \cdot f \cdot g+d \cdot h \cdot c-g \cdot e \cdot c \\
-a \cdot f \cdot h+C \cdot a \cdot i-C \cdot g \cdot c= \\
=a \cdot e \cdot i+b \cdot f \cdot g+d \cdot h \cdot c-g \cdot e \cdot c \\
-a \cdot f \cdot h+C \cdot(a \cdot i-g \cdot c)= \\
\quad=\left|\begin{array}{lll}
a & b & c \\
d & e & f \\
g & h & i
\end{array}\right|+C \cdot\left|\begin{array}{ll}
a & c \\
g & i
\end{array}\right|=\Delta+C \cdot\left|\begin{array}{ll}
a & c \\
g & i
\end{array}\right|
\end{gathered}
$$

The voltage transfer function $\mathrm{F}=\frac{\mathrm{V}_{2}}{\mathrm{~V}_{1}}$ will be given simply as (5).

$$
\begin{aligned}
& F=\frac{V_{3}}{V_{1}}=\frac{\Delta_{1: 3}}{\Delta_{1: 1}}=\frac{\left|\begin{array}{cc}
d & C+e \\
g & h
\end{array}\right|}{\left|\begin{array}{cc}
C+e & f \\
h & i
\end{array}\right|}=\frac{d \cdot h-g \cdot e-g \cdot C}{e \cdot i-h \cdot f+i \cdot C}= \\
& =\frac{\left|\begin{array}{ll}
d & e \\
g & h
\end{array}\right|-g \cdot C}{\left|\begin{array}{ll}
e & f \\
h & i
\end{array}\right|+i \cdot C}=\frac{\Delta_{1: 3}-C \cdot \Delta_{1,2: 3,2}}{\Delta_{1: 1}+C \cdot \Delta_{1,2: 1,2}}=\frac{\Delta_{1: 3}+C \cdot \Delta_{1,2: 2,3}}{\Delta_{1: 1}+C \cdot \Delta_{1,2: 1,2}}
\end{aligned}
$$

Thus sensitivity $\frac{\partial \mathrm{F}}{\partial \mathrm{C}}$ will be given as following formula (6).

$$
\frac{\partial F}{\partial C}=\frac{\partial}{\partial Y} \frac{d \cdot h-g \cdot e-g \cdot C}{e \cdot i-h \cdot f+i \cdot C}=
$$$$
=\frac{-g \cdot(e \cdot i-h \cdot f+i \cdot C)-i \cdot(d \cdot h-g \cdot e-g \cdot C)}{(e \cdot i-h \cdot f+i \cdot C)^{2}}=
$$

$=\frac{-g \cdot e \cdot i+g \cdot h \cdot f-g \cdot i \cdot C-i \cdot d \cdot h+i \cdot g \cdot e+i \cdot g \cdot C}{(e \cdot i-h \cdot f+i \cdot C)^{2}}=$ $=\frac{g \cdot h \cdot f-i \cdot d \cdot h}{(e \cdot i-h \cdot f+i \cdot C)^{2}}=\frac{h \cdot(g \cdot f-i \cdot d)}{(e \cdot i-h \cdot f+i \cdot C)^{2}}=$

$=-\frac{\Delta_{1: 2}}{\Delta_{1: 1}} \cdot \frac{\Delta_{1,2: 1,3}}{\Delta_{1: 1}}=-T_{1,2} \cdot T_{2,3}$

where first member $\frac{\mathrm{g} \cdot \mathrm{f}-\mathrm{i} \cdot \mathrm{d}}{\mathrm{e} \cdot \mathrm{i}-\mathrm{h} \cdot \mathrm{f}+\mathrm{i} \cdot \mathrm{C}}=\frac{\Delta_{1: 2}}{\Delta_{1: 1}}=\mathrm{T}_{1,2}$ is a partial transfer function from the node 1 to the node 2, the second one member i.e. $\frac{\mathrm{h}}{\mathrm{e} \cdot \mathrm{i}-\mathrm{h} \cdot \mathrm{f}+\mathrm{i} \cdot \mathrm{C}}=\frac{\Delta_{1,2: 1,3}}{\Delta_{1: 1}}=\mathrm{T}_{2,3} \quad$ is $\quad$ a partial transfer function from the node 2 to the node 3 , thus can be written (7)

$$
\frac{\partial \mathrm{F}}{\partial \mathrm{C}}=-\mathrm{T}_{1,2} \cdot \mathrm{T}_{2,3}
$$

As can be seen, the derivation is multiply of two transmission functions, (7) can be generalized in form (8)

$$
\frac{\partial \mathrm{F}_{\mathrm{kq}}}{\partial \mathrm{C}_{\mathrm{ji}}}=-\mathrm{T}_{\mathrm{iq}} \cdot \mathrm{T}_{\mathrm{kj}}
$$

Thus, relative sensitivity is (9)

$$
\mathrm{S}_{\mathrm{C}_{\mathrm{ji}}}^{\mathrm{F}_{\mathrm{kq}}}=-\frac{\mathrm{C}_{\mathrm{ji}}}{\mathrm{F}_{\mathrm{kq}}} \cdot \mathrm{T}_{\mathrm{iq}} \cdot \mathrm{T}_{\mathrm{kj}} \cdot
$$

These relationships (7), (9) given for non-switched circuits in [7], [8] can be therefore used for switched circuits, as well.

However, the graph solution requires finding a graph that includes all switching phases. The circuit must be described by a graph showing the fourport. The construction of the graph using transformation graphs and two-graphs for switched capacitors and switched currents circuits of required properties was described in [9].

\section{Example}

In this section an example concerning the symbolic analysis of the switched capacitor circuit

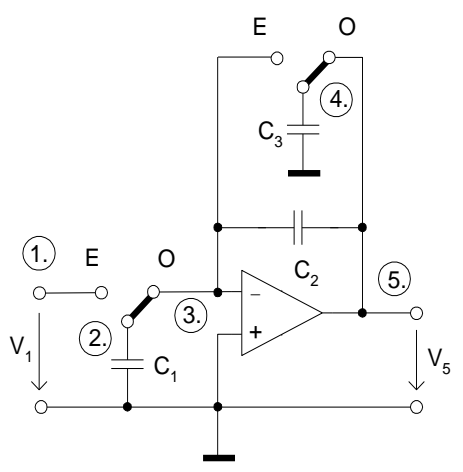

Fig. 2. The determination of the members Cji, Ckl.

is presented to show that the proposed method is applicable to relative sensitivity analysis of the switched circuits. Let is find the relative
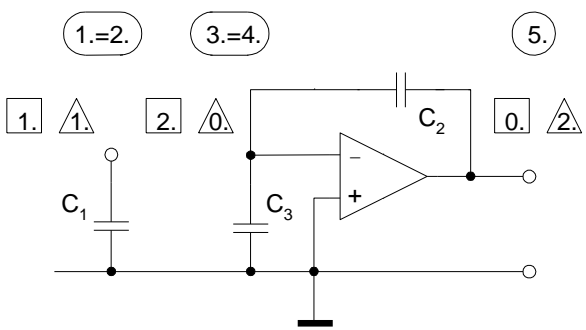

$2 .=3$.
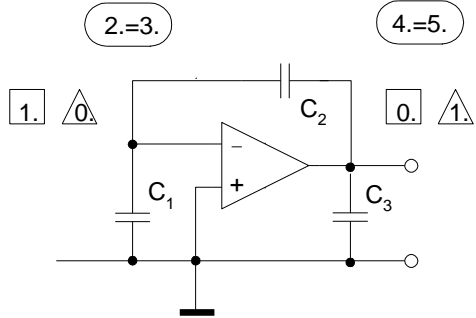

Fig.3. The first step of fully-graph sensitivity solutions. 


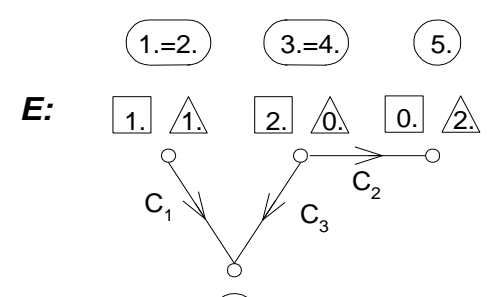

(0.)

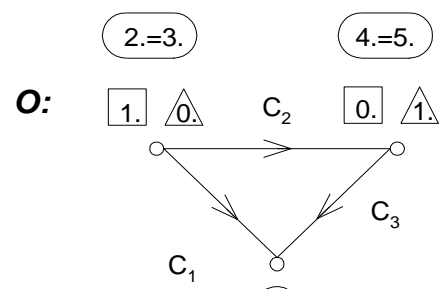

(0.)

Fig. 4. The second one step of construction of the summa graph: graphs for even and odd phases

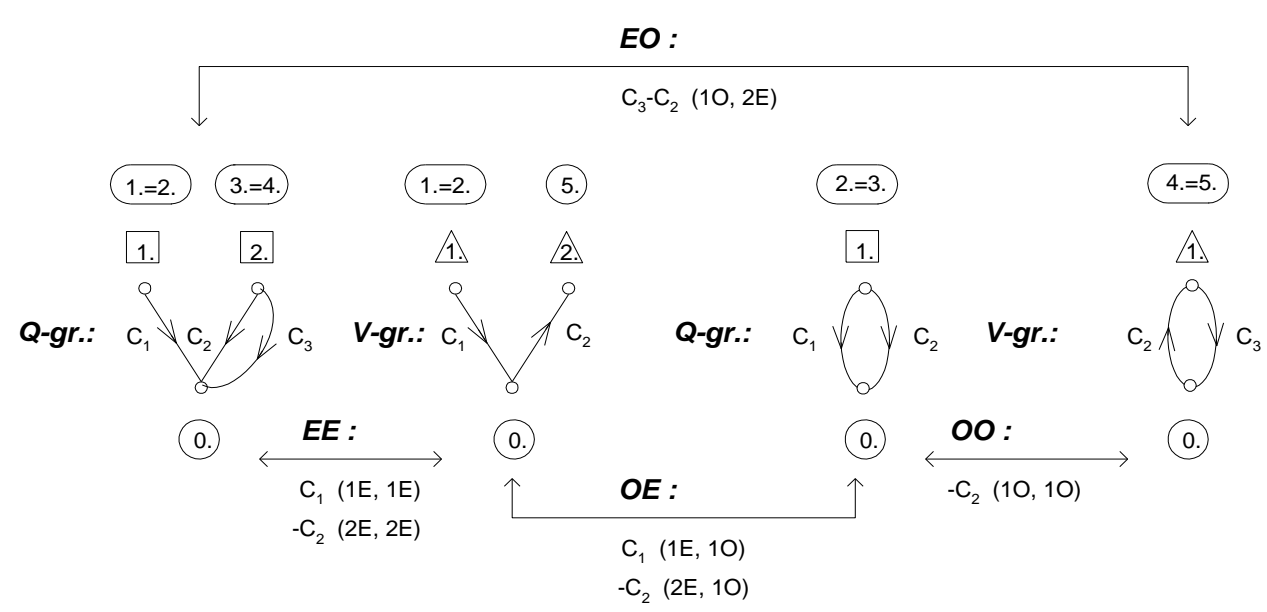

Fig. 5. The second one step of construction of the summa graph

sensitivity $\mathrm{S}_{\mathrm{C}_{1}}^{\mathrm{F}_{30, \mathrm{E}}}$ of the voltage transfer function $\mathrm{F}_{3 \mathrm{O}, \mathrm{IE}}$ (i.e. to node 3 in phase $\mathrm{O}$ from node 1 in phase E) of the SC circuit shown in Fig.2. The two-graph method will be used for solutions

First we draw a partial diagram for the even phase odd phases separately by the algorithm described in [8]. These diagrams are in Fig.3, where the node numbers in the squares are the numbers of the nodes of the charge Q-graph and the node numbers in the triangles are the numbers of the nodes of voltage $\mathrm{V}$-graph after re-numbering the nodes, caused according to the rules stated in [8] by the operational amplifier.

To the diagrams for individual phases, we can assign directed graphs drawn in Fig.4. For orientation there are the original numbers of nodes from the diagram in Fig. 2 in the circles.

An ideal operational amplifier then causes merging of the nodes 3 and 0 in the voltage $\mathrm{V}$ graph and merging of the nodes 5 and 0 in the charge Q-graph, as is described in [8], [9]. For both even and odd phases it is necessary to draw a special voltage and charge graphs.

These graphs are in Fig.5.

As is described in [2], [5], [6] determinant $\Delta$ of the matrix $\mathbf{Y}$ (or the matrix $\mathbf{C}$ in this case switched capacitors circuits) of the circuit is given by $(10)$

$$
\Delta=\sum_{W} \pm(\text { product of capacitors })
$$

where $\mathrm{W}$ is given as (11)

$$
\begin{aligned}
& W=\left\{\begin{array}{rrr}
\text { set } & \text { of } & \text { spanning } \\
\text { trees } & \text { of } & V-\text { graph }
\end{array}\right\} \cap \\
& \cap\left\{\begin{array}{ccc}
\text { set } & \text { of } & \text { spanning } \\
\text { trees } & \text { of } & Q-\text { graph }
\end{array}\right\}
\end{aligned}
$$

In other words, there is a term in the expression for $\Delta$ corresponding to each spanning tree that is common to the charge (Q-gr.) and voltage graphs (V-gr.).

This principle is used to construction summary M-C graph. Summary M-C graph is now constructed by first finding the incomplete common skeletons of the V-graph and the Q-graph in the even phase and in the odd one: in the even phase there is one incomplete common skeleton formed by the $C_{l}$ element connected to the node 1 of both graphs, another incomplete skeleton is formed by the $C_{2}$ element connected to the node 2 of both graphs.

But as the arrows in the Q-graph and the Vgraph aim in the opposite direction, the $C_{2}$ element has a negative sign, i.e. there will be $-C_{2}$. In the odd phase there is an incomplete skeleton formed by $C_{2}$ connected to the $1^{\text {st }}$ node, the arrows in the Q-graph and the V-graph aim in the opposite directions, so $C_{2}$ has a negative sign $-C_{2}$. Thus obtained loops of summary Mason-Coates graph are in Fig.5.

The common skeleton of the V-graph in the $\mathrm{E}$ phase and of the Q-graph in the $\mathrm{O}$ phase is formed by the $C_{l}$ element, whose graph goes from the node 1 in the even phase and from the node 1 in the odd phase, and by the $C_{2}$ element, but as the arrows at $C_{2}$ in the $\mathrm{Q}$-graph and $\mathrm{V}$-graph go against each 
other, the $C_{2}$ element has got a negative sign, i.e. there is $-C_{2}$. Thus the graph for the $\mathrm{OE}$ phase is given. In the EO phase we look for common incomplete skeletons from the Q-graph in the E

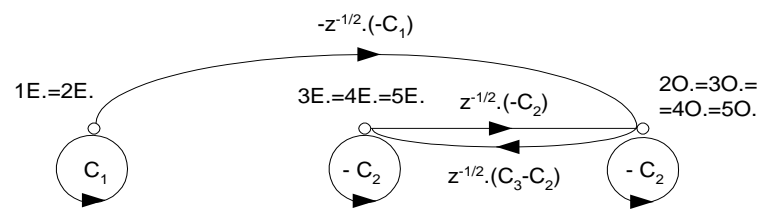

Fig. 6. The second one step of construction of the summa graph

phase and from the $\mathrm{V}$-graph for the $\mathrm{O}$ phase. There are two branches going parallel with transfers $\mathrm{C} 2$ and $C_{3}$, while the arrows at $C_{2}$ go in opposite directions so in the sum of these parallel branches $C_{2}$ will have a negative sign: $C_{3}-C_{2}$.

After completing the graph will get the form shown in Fig.6.

In the last step of the sensitivity solutions, the rule (9) is applied. The relative sensitivity $S_{C_{1}}^{F_{30,1 E}}$ thus will be calculated as (12).

$$
\begin{aligned}
& \mathrm{S}_{\mathrm{C}_{1}, 1 \mathrm{E}}^{\mathrm{F}_{3 \mathrm{E}}}=\frac{\mathrm{C}_{1}}{\mathrm{~F}_{3 \mathrm{O}, 1 \mathrm{E}}} \cdot \frac{\partial \mathrm{F}_{3 \mathrm{O}, 1 \mathrm{E}}}{\partial \mathrm{C}_{1}}=\frac{\mathrm{C}_{1}}{\mathrm{~F}_{3 \mathrm{O}, 1 \mathrm{E}}} \cdot \frac{\partial \mathrm{F}_{3 \mathrm{O}, 1 \mathrm{E}}}{\partial \mathrm{C}_{1}} \cdot \frac{\partial \mathrm{C}_{3 \mathrm{O}, 1 \mathrm{E}}}{\partial \mathrm{C}_{3 \mathrm{O}, 1 \mathrm{E}}}= \\
& =\frac{\mathrm{C}_{1}}{\mathrm{~F}_{3 \mathrm{O}, 1 \mathrm{E}}} \cdot \frac{\partial \mathrm{F}_{3 \mathrm{O}, 1 \mathrm{E}}}{\partial \mathrm{C}_{3 \mathrm{O}, 1 \mathrm{E}}} \cdot \frac{\partial \mathrm{C}_{3 \mathrm{O}, \mathrm{IE}}}{\partial \mathrm{C}_{1}}= \\
& =\frac{\mathrm{C}_{1}}{\mathrm{~F}_{3 \mathrm{O}, 1 \mathrm{E}}} \cdot \mathrm{T}_{1 \mathrm{E}, 1 \mathrm{E}} \cdot \mathrm{T}_{3 \mathrm{O}, 3 \mathrm{O}} \cdot \frac{\partial \mathrm{C}_{3 \mathrm{O}, 1 \mathrm{E}}}{\partial \mathrm{C}_{1}}= \\
& \mathrm{C}_{1} \\
& =\frac{-z^{-\frac{1}{2}}\left(-C_{1}\right) \cdot\left(-C_{2}\right)}{\left(-C_{2}\right) \cdot\left(-C_{2}\right)-z^{-\frac{1}{2}}\left(-C_{2}\right) \cdot z^{-\frac{1}{2}}\left(C_{3}-C_{2}\right)} \\
& \cdot \frac{\left(-\mathrm{C}_{2}\right)\left(-\mathrm{C}_{2}\right)-\mathrm{z}^{-\frac{1}{2}}\left(-\mathrm{C}_{2}\right) \mathrm{z}^{-\frac{1}{2}}\left(\mathrm{C}_{3}-\mathrm{C}_{2}\right)}{\left(-\mathrm{C}_{2}\right) \cdot\left(-\mathrm{C}_{2}\right)-\mathrm{z}^{-\frac{1}{2}}\left(-\mathrm{C}_{2}\right) \cdot \mathrm{z}^{-\frac{1}{2}}\left(\mathrm{C}_{3}-\mathrm{C}_{2}\right)} \frac{\partial\left[-\mathrm{z}^{-\frac{1}{2}}\left(-\mathrm{C}_{1}\right)\right]}{\partial \mathrm{C}_{1}}= \\
& =\frac{\mathrm{C}_{1}}{-\mathrm{z}^{-\frac{1}{2}}\left(-\mathrm{C}_{1}\right)\left(-\mathrm{C}_{2}\right)}\left[-\left(-\mathrm{z}^{-\frac{1}{2}}\right)\right]\left(-\mathrm{C}_{2}\right)=\frac{-\mathrm{z}^{-\frac{1}{2}} \mathrm{C}_{1} \mathrm{C}_{2}}{-\mathrm{z}^{-\frac{1}{2}} \mathrm{C}_{1} \mathrm{C}_{2}}=1
\end{aligned}
$$

where $\mathrm{T}_{1 \mathrm{E}, 1 \mathrm{E}}, \mathrm{T}_{3 \mathrm{O}, 3 \mathrm{O}}$ are partial transfer functions from summary graph (see Fig.5), there are calculated from Mason's formula (13).

$$
\mathrm{T}_{\mathrm{ab}}=\frac{\mathrm{x}_{\mathrm{b}}}{\mathrm{y}_{\mathrm{a}}}=\frac{\sum_{\mathrm{i}} \mathrm{P}_{\mathrm{ab}}^{(\mathrm{i})} \cdot \Delta_{\mathrm{ab}}^{(\mathrm{i})}}{\Delta}
$$

\section{Conclusion}

The problem of sensitivity determination has been investigated in a great number of publications during the last several decades [15], [16], [17], [18],
[19], [20], [21] and many others. A typical problem here is the determination of the derivates in the sensitivity expressions and its decision had been searched in different ways.

A fully graph method for relative symbolic sensitivity analysis of the switched circuits is described.

This method requires no intermediate nullor models, which is an auxiliary step in the conventional solution, the method does not require the capacitance (and/or conductance) matrix assembling. The disadvantage of graph methods so far described by prof. Moschytz [20] and prof. Toumazou [4] and many others, is the impossibility to find the transfer and hence the sensitivity between the different switching phases. Using the summary graph eliminates this disadvantage.

The transformation graphs method can also be used to construct a summary graph, this construction is described in detail in [9]. The example is solved for the SC circuit but this method is also applicable to SI circuits due to the similarity of relationships (1) and (2), too. The construction of a summary graph for the SI circuit is described in detail in [23], as well.

Since all other known graphical solutions of switching capacitor circuits do not differentiate the input nodes for each phase separately and the output nodes for different phases separately, these methods can not be used to solution by graphs sensitivity to change the parameter between the phases. Such a solution is only possible by matrix methods, not by known graph methods, so the described graph method with the summa graph with other existing graphical methods cannot be compared, because this comparison is impracticable.

\section{References}

[1] SHI, G. Graph-Pair Decision Diagram Construction for Topological Symbolic Circuit Analysis. IEEE Transactions on Computer Aided Design of Integrated Circuits and Systems. vol.32, no.2, pp.275288. Feb.2013.

[2] PIERZCHALA, M., FAKHFAKH, M. Transformation of LC filters to active $R C$ circuits via the two-graph method. Microelectronic Journal, vol.42, no.8, pp.99910015, Aug.2011.

[3] RODRIGUES-CHAVEZ, S., PALMARODRIGUEZ, A., A., TLELO-CUAUTLE, E., TAN, S., X. Graph-based symbolic and symbolic sensitivity analysis of analog integrated circuits. Analog/RF and MixedSignal Circuit Systematic Design. Springer, Lecture Notes in Electrical Engineering, vol.233, pp. 101-122, 2013. 
[4] TOUMAZOU, C., BATTERSBY, N. C., HUGHES, J. B. Switched-currents an analogue technique for digital technology. London (UK): Peter Peregrinus Ltd., 1993. ISBN: 0863412947.

[5] DOSTÁL,T., MIKULA,J. Signal-Flow Graph Network Analysis. Radioengineering, 1992, vol.1, no.1, p.14-20.

[6] ČAJKA, J., KVASIL, J. Theory of circuits. Linear and linearized circuits. Praha/Bratislava (CS): SNTL/ALFA, 1979.

[7] ASENOVA, I., BALIK, F. Multiparameter symbolic sensitivity analysis enhanced by nullor model and modified Coates flow graph. Advanced in electrical and electronic engineering, 2013, vol.11, no.2, p.108-115.

[8] ASENOVA, I. calculation of first-, secondorder and multiparameter symbolic sensitivity of active circuits by using nullor model and modified Coates flow graph. International journal of microelectronics and computer science, 2011, vol.2, no.4, p.129-135.

[9] BRTNÍK, B. Comparison of the full-graph method switched circuit solution. Przeglad Elektrotechniczny, 2012, no.6, p.332-336.

[10] DOSTÁL, T. The analysis of active components containing switched capacitors by nodal voltage method and transformations. Electronic horizon, 1984, vol.45, no.1, p.2127.

[11] MIKULA, J., DOSTÁL, T. A design approach to capacitor-switched networks, using MC graphs. Electronic horizon, 1985, vol.46, no.12, p. 560-565

[12] POSPÍŠIL, J., DOSTÁL, T. Electronic circuits and systems I. Brno (CS): BUT, 1991.

[13] BRTNÍK, B. Solving switched circuits by graph methods. Praha (CZ): BEN, 2011.

[14] BRTNÍK, B. Graph only solution of SC circuits by means two-graph. In Proceedings of the $15^{\text {th }}$ WSEAS international conference on circuits (CSCC). 2011, Corfu Island, Greece, p.100-105.

[15] PALMA RODRIGUEZ, A., A., TLELOCUAUTLE, E., RODRIGUEZ-CHAVEZ, S. DDD-based symbolic sensitivity analysis of active filters. In Proceedings of the $8^{\text {th }}$ International Caribbean Conference on Devices, Circuits and Systems (ICCDCS), 2012, p. 48-51.

[16] NENOV, G., A. A comparative study on symbolic network sensitivity analysis by using some kinds of signal-flow graphs. In Proceedings of the $5^{\text {th }}$ International conference on circuits, system, control, signals (CSCS'14). 2014, Salerno, Italy, p.5463.
[17] OSOWSKI, S. Signal flow graphs for determination of higher order sensitivities of circuit functions. Proceedings of the European_Conference on Circuits Theory_and Design. 2011, pp.446-449.

[18] STENBAKKEN, G. N., STARZYK, J. A. Diakoptic and large change sensitivity analysis. IEE PROCEEDINGS-G. Vol. 139. No.1., 1992, pp.114-118.

[19] IORDACHE, M., DUMITRIU, L., NICULAE, D. On the Sensitivity Analysis of Analog Circuits. Annals of the University of Craiova, Electrical Engineering series, 2008, No. 32, pp.11-16.

[20] DABROWSKI, A., MOSCHYTZ, G. S. Direct Analysis of Multiphase SwitchedCapacitor Networks Using Signal-Flow Graphs. IEEE Transactions on Circuits and Systems, vol. 37, no.5, pp.594-607, May 1990.

[21] LI, P.M. Sensitivity Analysis of Large Linear Networks Using Symbolic Programs, Proceedings of The IEEE International Symposium on Circuits and Systems ISCAS '92, 10-13 May 1992, vol.3, pp.1145-1148.

[22] MAO, J.-F., KUH, E. S. Fast Simulation and Sensitivity Analysis of Lossy Transmission Lines by the Method of Characteristics, IEEE Trans.Circuits and Systems I: Fundamental Theory and Applications, vol. 44, iss. 5, May 1997.

[23] BRTNÍK, B. Assembling a formula for current transferring by using a summary graph and transformation graphs. Journal of electrical engineering. 2013, vol.64, no.5, p. 334-336.

Contribution of Individual Authors to the Creation of a Scientific Article (Ghostwriting Policy)

The author contributed in the present research, at all stages from the formulation of the problem to the final findings and solution.

\section{Sources of Funding for Research Presented in a} Scientific Article or Scientific Article Itself

No funding was received for conducting this study.

\section{Conflict of Interest}

The author has no conflict of interest to declare that is relevant to the content of this article.

Creative Commons Attribution License 4.0 (Attribution 4.0 International, CC BY 4.0)

This article is published under the terms of the Creative Commons Attribution License 4.0 https://creativecommons.org/licenses/by/4.0/deed.en 